\title{
Advanced Computational Dissection for Lumbar Cadaveric Specimens with Applications
}

\author{
Francisco Casesnoves"1 \\ ${ }^{*} \mathrm{PhD}$ Engineering, MSc Physics, MD. Independent Research Scientist Engineering-Physics-Software and \\ Medical Bioengineering Devices. IAAM (International Association of Advanced Materials). COE Tallinn \\ University of Technology, Tallinn, Harjumaa, Estonia
}

\begin{abstract}
Previous contributions dealt with demonstration of software-computational methods (CAD) to digitalize cloud data, and filter numerically them. Subsequently, simulate and fit mathematically the anterior and lateral facet vertebral body morphometry of cadaveric lumbar spines. This advanced study presents three computational dissection methods for new/different lumbar cadaveric specimens. Namely, Region of Interest (ROI) software-method, Programming-dissection selection technique, and Plane-Segmentation dissection. Results demonstrate computational images of several ROIs from L2 to L5 anterior facets, programming-dissection of complete specimen. Third findings group prove planar dissections for a long cadaveric specimen. Additional results/outcomes emerge from anatomical analysis of the cadaveric specimens. Applications to orthopedics tools and prostheses, surgical robotics, spinal stabilization instrumentation, spine-rehabilitation apparatus and Forensic Robotics [Casesnoves, 2020] comprise additional findings. Results in prehypotheses theory for spine-biomechanical evolution are indicated.

Keywords : Software Engineering, Surfactal Programming, CAD (Computer Aided Design), CAM (Computer Aided Manufacturing), ROI, Anatomical Cadaveric Simulations, Biomechanics, Bioengineering, Spinal ComputationalSurgery, Spinal Ligaments, Spinal Anterior Longitudinal Ligament (ALL), Surgery Robotics Integrated Systems
\end{abstract}

Article Info

Volume 7, Issue 2

Page Number: 83-97

Publication Issue :

March-April-2021

\section{Article History}

Accepted : 15 March 2021

Published : 25 March 2021

\section{INTRODUCTION}

Computational Surgery field, both for investigation and clinical practice, has emerged as a standard specialization in modern surgery. Anatomical specimens are useful to obtain numerical data and imaging information for CAD and CAM. In a previous article [3], the initial stages to set the base of computational dissection were proven. Complementary, Robotics Surgery branch constitutes an additional super-specialization to optimize the precision, efficiency and efficacy in particular surgical tasks. The principle of minimal invasive surgery is maintained, because the operating field 
simulation database prevents complications and unnecessary tasks.

Surfactal Computer Aided Design (CAD) and Computer Aided Manufacturing (CAM) methods have been incorporated to modern hospital surgery divisions. The statistical study of vertebral shape, facets, ligaments, curvature, geometry at different stages of any disease or lifetime can provide information for surgical theatre pre-post-operative planning or instrumentation manufacturing-and also for evaluation of incidence/prevalence of spinal pathologies. CAD and CAM are widely used for design of orthopedics apparatus. For instance, new prostheses, spinal screws, stabilization kits, artificial intervertebral disks, grips, etc.

When using CAD in design of surgical tools or prostheses, the fitting error can be significantly reduced-the larger statistical database, the less fitting error when prostheses are set.

Therefore, this study, based on previous contributions, [3], presents advanced computational dissection methods for lumbar spine surfactal imaging records extraction. The computational method is based on experimental scanning data from lumbar cadaveric specimens. Once the scanning large-scale matrix is obtained, its $3 \mathrm{D}$ numerical data is implemented in imaging programming-software. Program design is combines modified subroutines and patterns to optimize visualization precision. This innovative method offers three main sub-methods or new techniques. Namely, dissection/visualization of ROIs, Computational Dissection of spinal segments, and Plane-dissection of 3D specimen images. Starting from previous studies [8-13,17], the proof that demonstrates the amount of biomedical-surgical information that can be obtained from computational surfaces of these anatomical samples is shown. For
Specimen 1, an anatomical study is presented with clinical and diagnosis conclusions.

The second part of the article shows a number of applications and pre-hypotheses derived from the first one. First, biomedical and bioengineering modern applications. Second, Pre-hypotheses of spinal evolution related to computational spinal surgery, [Casesnoves, 2019]. And third, an update of applications of these findings in surgical robotic integrated systems. Surgical Robotics section shows concepts of Forensics Robotics also, [Casesnoves, 2019-20].

In summary, this study proves utility and efficacy of three computational dissection methods for 3D image settings of spinal cadaveric samples. Further, prehypotheses and projections towards future surgical applications are indicated/explined. These are biomedical upcoming applications, evolutionary concepts pre-hypotheses, and surgical robotics and Forensic Robotics usage concepts.

\section{ANATOMICAL SPECIMENS AND SCANNING METHODS}

The CAD surfactal fit was obtained from different anterior vertebral body anatomic cadaveric samples. The cloud data of these cadaveric samples, as in [812], was obtained using the 3D Scanner Digitizer (high resolution $\simeq 10^{-7} \mathrm{~m}$ ). The data obtained of the spine surfaces had $\simeq 10^{5}$ points for each specimen. The specimen of Figure 4 has about 15,300 3D points. The specimen for ROIs and computational dissection of Figures 1-3 has about 12,000 3D cloud points.

Cloud point number is reduced from $\simeq 10^{5}$ to $\simeq 10^{4}$ to increase the visualization program speed. The reduction of points was performed by interpolation software, taking approximate middle points among intervals. In previous contributions, extent 
developments of the specimens for computational programs were carried out [8-12]. However, in this paper the focus is on a longer cadaveric sample to show the disk hernias sharply. The study has the objectives: the programming design, types of dissection demonstrations, anatomical analysis, and biomedical applications/pre-hypotheses.

\section{PROGRAMMING-SOFTWARE METHODS}

The programming method was based on both subroutines and a group of codes to set spinal images accurately. It was rather complicated the setting of around 2000 cloud points and at the same time to obtain a running time short. However, this difficulty was sorted mainly with two methods. Programming techniques are based on previous publications and literature $[2,4,5,6,7,8-12]$. First, selecting the fastest subroutines for 3D imaging. Second, getting an optimal order for the program sentences to avoid unnecessary operations, loops, and reiterations of calculus.

The programming method for ROI selection is more complicated. The cloud points have to be selected from the imaging matrix after the simulation was done. With these point extraction the ROI image is implemented-provided a good fit for tile size is done. Even more difficult is the programming-dissection. First, the matrix cloud points at dissection-gaps of specimen have to be extracted. Second, points at matrix to separate vertebras from disks are implemented. Finally, all data is loaded into a single matrix and setting for $3 \mathrm{D}$ visualization.

The average running time for a cadaveric image was 2-6 seconds. The image tools time to start to work was about 2-5 minutes. The time to make a matrix ROI image is about 10 minutes. The time to obtain a complete computational dissection is about 30 minutes. The division of numerical intervals for tiles in complete lumbar specimen image was selected about 0.5 for optimal visualization and not long running time. For ROIs imaging it was [0.8-1.0].

\section{RESULTS FOR PROGRAMMING DISSECTION AND ROI DISSECTION}

A ROI is defined as a part of the 3D or 2D image which constitutes practical/special interest for further study. Its image-observation and numerical data has several bioengineering applications [5-9]. To obtain a ROI, it is necessary, firstable, the complete image visualization of the specimen. With the imaging tools, the ROI coordinates are selected. Then, these numerical data is extracted from the 3D image matrix. After that, a new image for ROI is obtained. Figures 1 and 2, two ROIs of specimen of Figure 3 are selected and visualized. Transversal processes are sharply obtained.

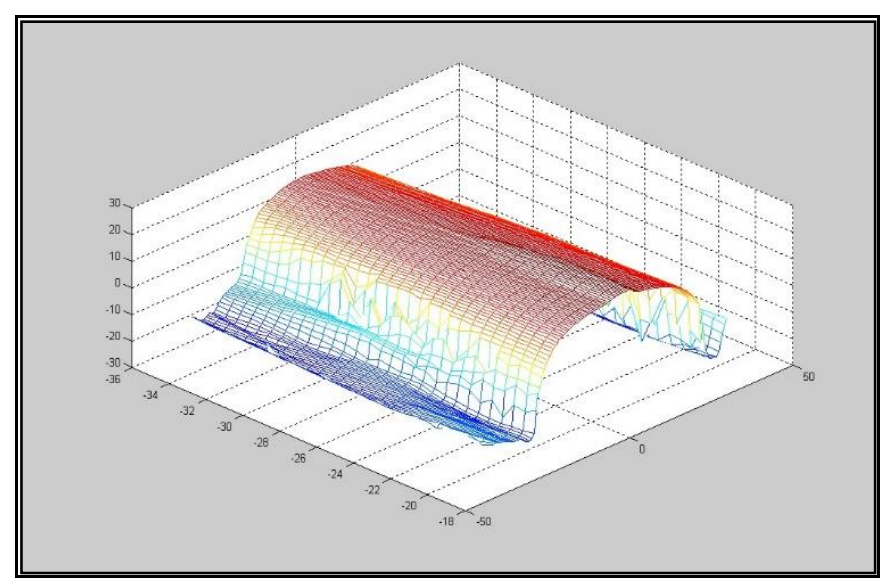

Figure 1,-L4 complete anterior facet ROI selection. L4 vertebral body is usually the thickest. In this image, tiles intervals are set wider. The lines that can be observed at the dome top figure correspond to ALL. Transversal process image is clear. Anterior facet bone surface, as it is known [1, 8-12], is not a totally smooth surface. 


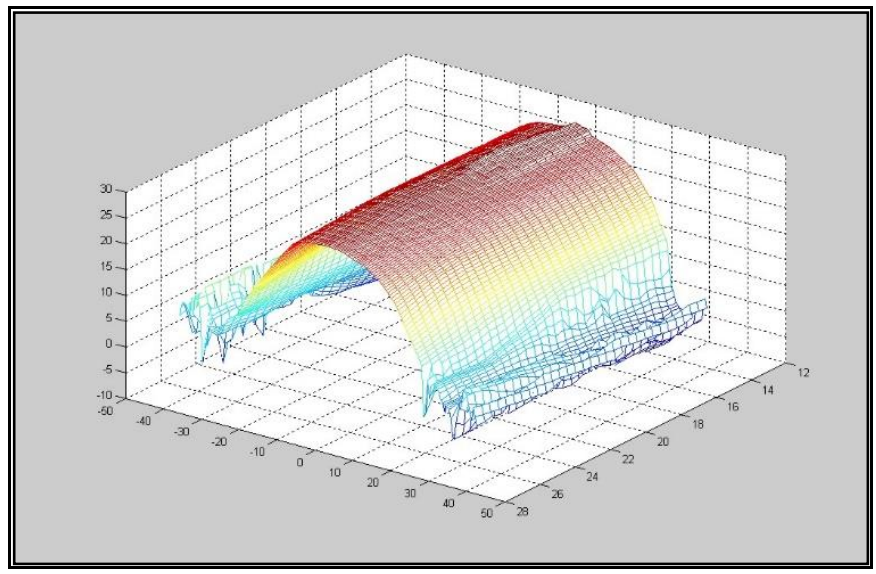

Figure 2.-L5 ROI computational dissection. It is narrower than the L4 ROI. The superior part is wider. Transversal process is shorther and thicker compared to L4 Figure 1..

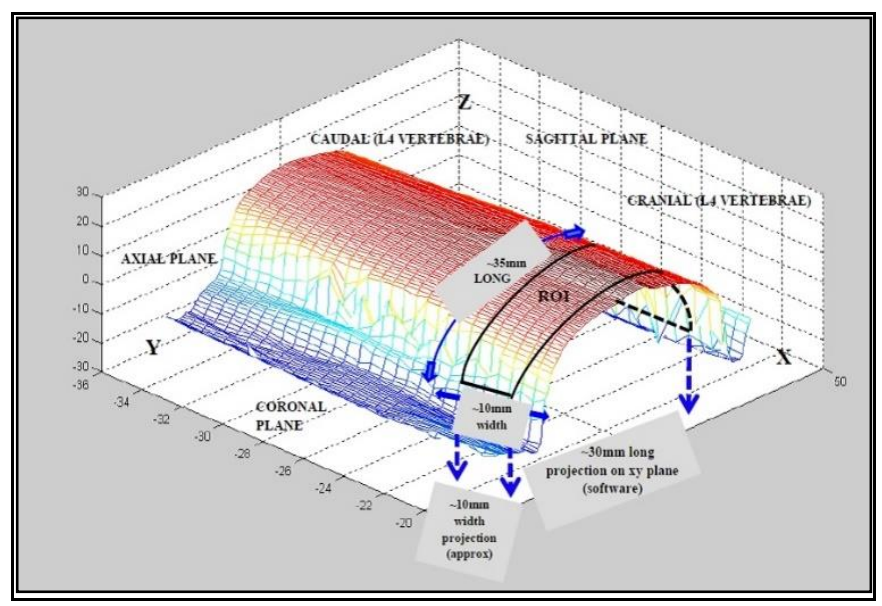

Figure 3.-Computationally-modified ROI from $[8,14]$. Computational dissection directions are clearly specified. Measurements of ROI, based on scanning data scale, are set. This computational dissection task is rather difficult and time consuming. Apart from that, to obtain a good figure with draw and measurement indications over is not simple. Transversal process can cause bias on curvature measurements.

Figure 4, the total computational dissection with an specimen for separation of vertebral segments and disks is shown. This task takes about 30-40 minutes. The 3D cloud point data matrix has to be modified to set gaps. Every specimen is different for this type of computational-anatomical study.

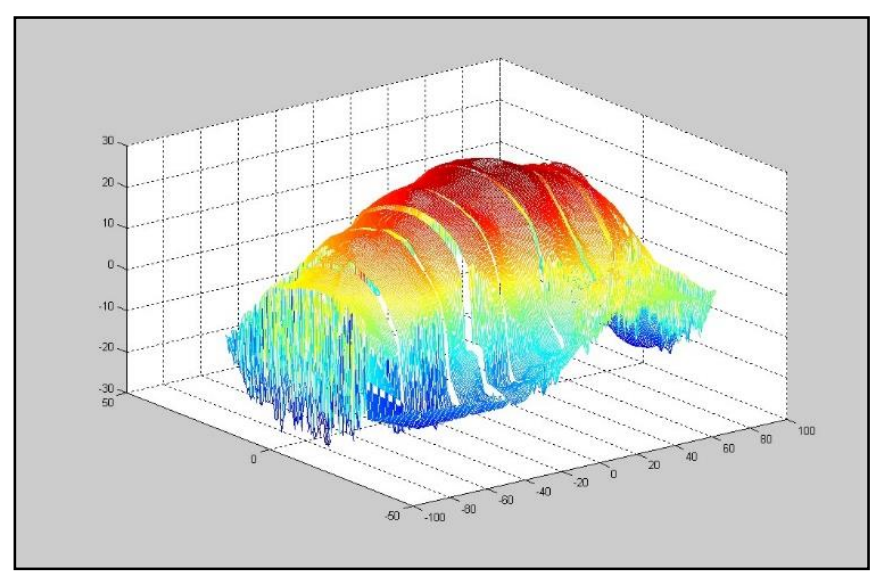

Figure 4.-Computational dissection separating all vertebras. Specimen cloud data comes from previous contribution [ref]. Vertebras and disks can be identified easily. The gaps were set working with the 3D image matrix.

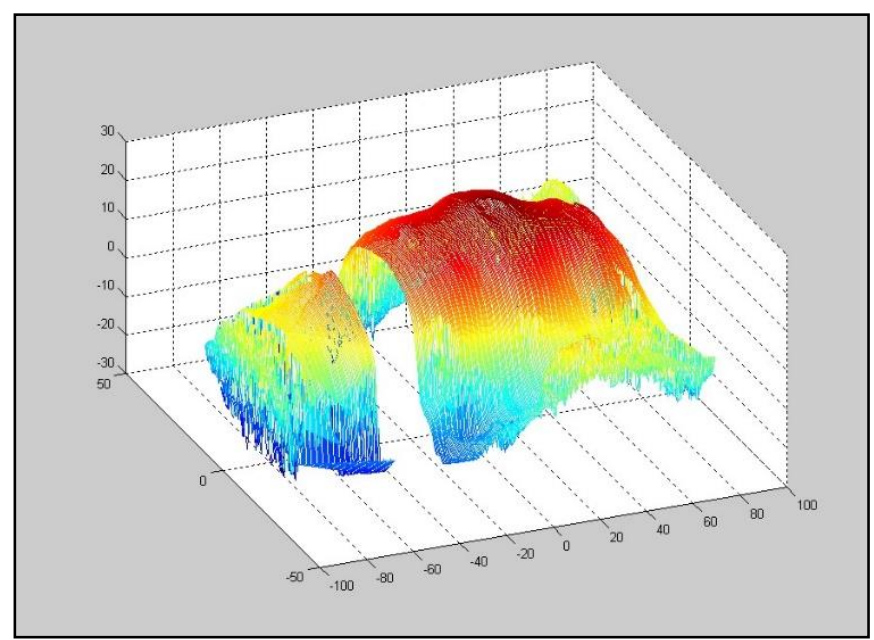

Figure 5.-Computational dissection with extraction of L2. The surface extracted was loaded in a separate 3D matrix to obtain an individual image of $\mathrm{L} 2$ facet.

\section{RESULTS FOR COMPUTATIONAL PLANE DISSECTIONS}

This section shows with plane dissection for a rather long specimen, Figure 6. Subsequently, an anatomical study is performed with details. Finally, a plane 
dissection for segments, disks and vertebras is shown. Figure 7, a right-lateral-oblique view is displayed. Figure 8 , the anatomical details are pictured and outlined. Observations of disk hernias, size and shape of vertebras are exposed. Appendix I shows larger images to compare these specimens with specimens of previous contributions [3].

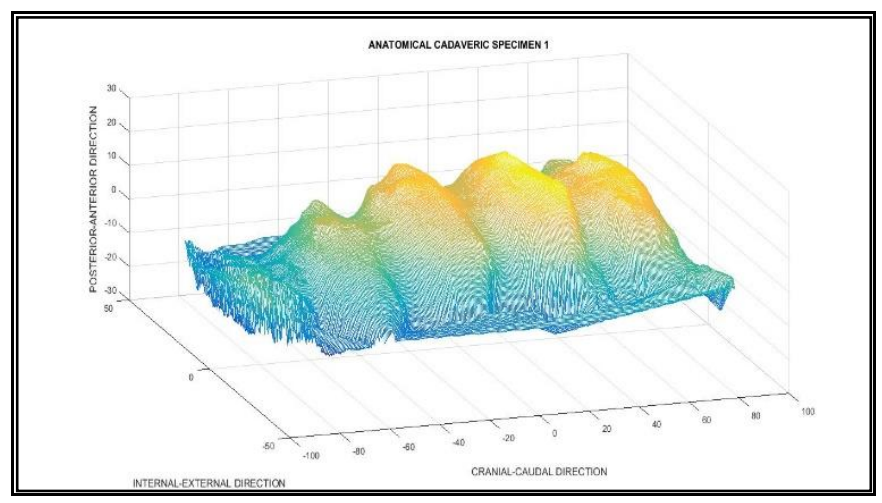

Figure 6.- Specimen 1 cadaveric reconstruction lateral-right view. It is a longer spine compared to specimens of previous publications $[6-9,14,15]$. The disks are emerging from face planes because there are multiple disk hernias. ALL traces can be visualized. Anatomical directions are set. From this CAD image, further analysis of vertebras, disks and ligaments are going to be detailed in Figure 2. Enhanced view to be compared to specimens of [2] is at Appendix I.Figure 1.The anatomical differences are significant.

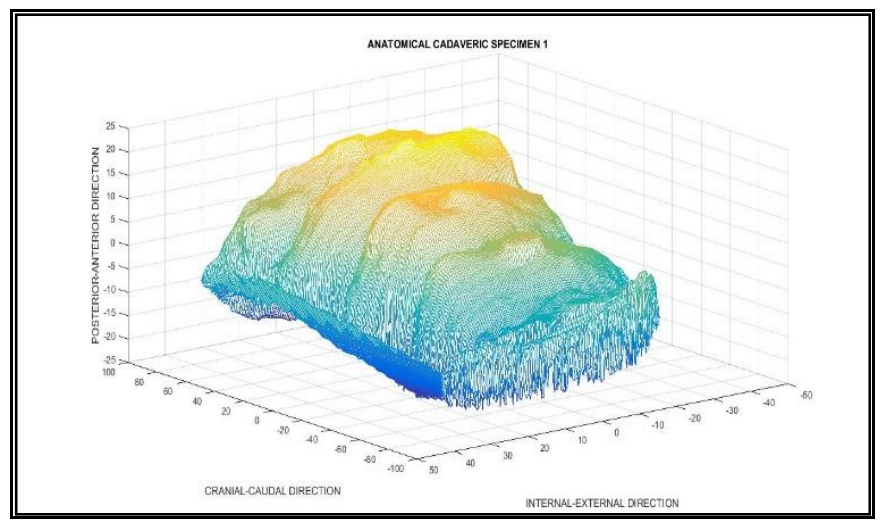

Figure 7.- Specimen 1 cadaveric reconstruction. This is a cranial-caudal view. Vertebral deformations are even more clear.

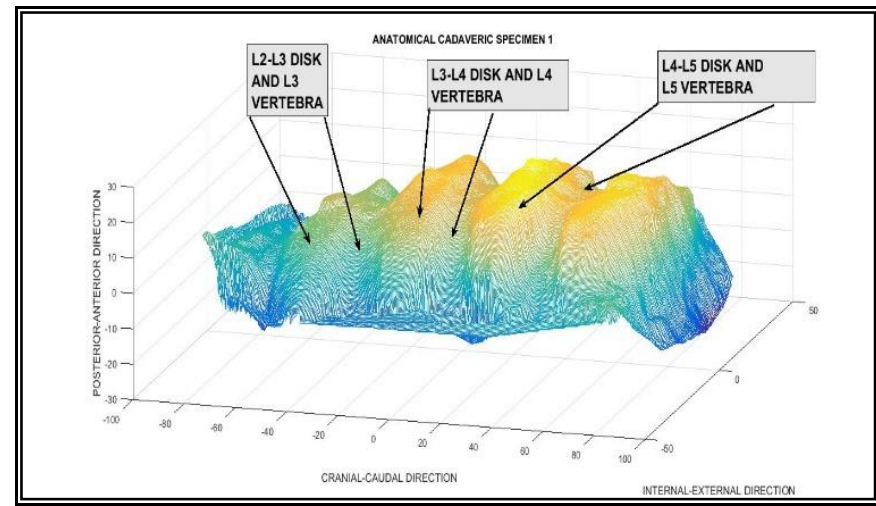

Figure 8.-Anatomical analysis of Specimen 1, lateralright view. Vertebras, disks and ALL traces are sharp. Enhanced view to be compared to specimens of [2] is at Appendix I.Figure 2.The anatomical differences are significant.

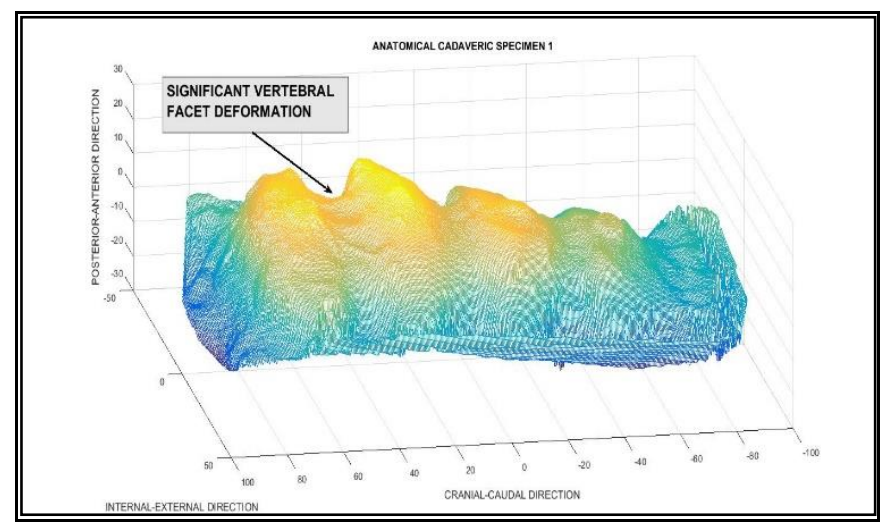

Figure 9.- Anatomical analysis of Specimen 1, lateralleft view. Vertebras, disks and ALL traces are sharp. Many times occurs in clinical practice that symptoms do not always correlate with vertebral and/or spine damage. That is, the patient, for example, has multiple disks hernias or vertebral deformations and does not experiment any significant pain and symptoms. 


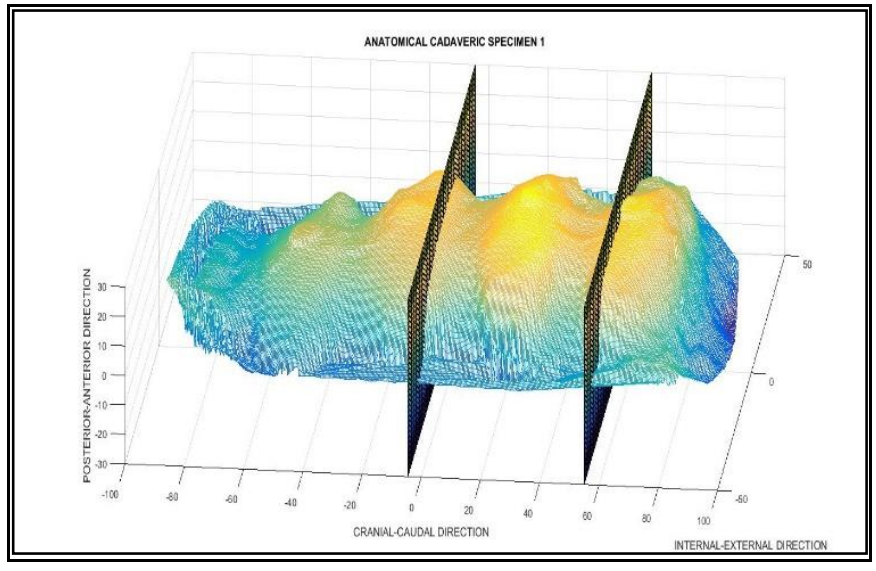

Figure 10.-Lateral-left view of the lumbar spine specimen. Computational plane dissection of segment L4-disk-L5 vertebral bodies in Specimen 1. It was intended to show the alteration of this important lumbar spine segment. Dissection planes are set to define the structure degeneration of L5 facet at left side. The pathological curvatures and concavities of L4 and L5 are clearly defined. Transversal processes can be seen, although not very clearly.

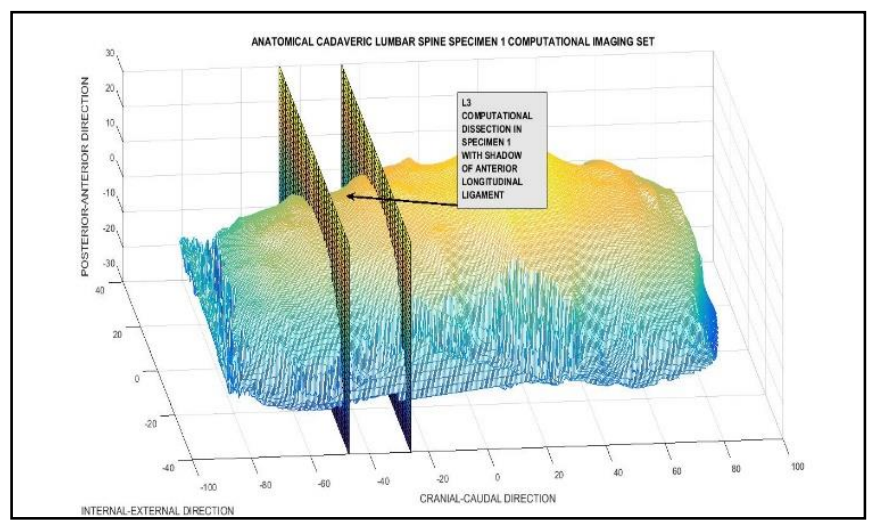

Figure 11.- Lateral-right view of the lumbar spine specimen. Computational plane dissection of segment L3 vertebral body in Specimen 1. It was intended to show also the alteration of this important lumbar spine facet. Dissection planes are set to define the structure degeneration of L3 facet at right side.
Table 1 shows an anatomical analysis of Specimen 1. The basic deductions that can be guessed from 3D images are explained. Specimen 1 is interesting because biomechanical consequences of age vertebral degeneration can be obtained.

\begin{tabular}{|c|c|}
\hline \multicolumn{2}{|c|}{$\begin{array}{c}\text { COMPUTATIONAL DISSECTION } \\
\text { ANATOMICAL } \\
\text { RESULTS SPECIMEN } 1\end{array}$} \\
\hline LENGTH & $\begin{array}{l}\text { Longer than previous } \\
\text { specimens }\end{array}$ \\
\hline $\begin{array}{l}\text { VERTEBRAL } \\
\text { FACETS }\end{array}$ & $\begin{array}{l}\text { Concavity and convexity } \\
\text { deformed, holes }\end{array}$ \\
\hline DISKS & Herniated all of them \\
\hline $\begin{array}{l}\text { ARTHROSIS } \\
\text { OSTEOPATHY } \\
\text { DEGENERATION }\end{array}$ & $\begin{array}{l}\text { Significant and affecting to } \\
\text { all vertebras }\end{array}$ \\
\hline $\begin{array}{l}\text { GEOMETRICAL } \\
\text { DISTRIBUTION }\end{array}$ & $\begin{array}{l}\text { Arthrosis changes are non- } \\
\text { symmetrically distributed } \\
\text { as it is usual in that } \\
\text { degenerative-disease }\end{array}$ \\
\hline $\begin{array}{l}\text { TRANSVERSAL } \\
\text { PROCESSES }\end{array}$ & $\begin{array}{l}\text { Can be observed although } \\
\text { not so clear compared to } \\
\text { ROIs }\end{array}$ \\
\hline ALL & $\begin{array}{l}\text { Traces visualized along all } \\
\text { specimen }\end{array}$ \\
\hline
\end{tabular}

Table1. Anatomical-computational study of Specimen 1 highlights.

\section{BIOMEDICAL-BIOENGINEERING APPLICATIONS}

Biomedical and Bioengineering applications of three types of computational dissection can be divided into theoretical and practical. Theoretical comprise all computational software and database for CAM and/or CAD of any prostheses, implant, apparatus, orthopedic stabilizer, etc. Also statistical data and CAD software for analysis of spinal pathologies-for example, incidence/prevalence of childhood spinal 
diseases evolution, statistics of elderly spinal diseases incidence, professional-risk of spinal damage, etc. Practical applications are extensive and varied. Table 2 presents them, from surgical theatre tools manufacturing till implants, artificial disks, stabilizers, pediatric orthopedics, etc. Table 2 shows a complete synopsis of biomedical applications.

One important application is the CAM design of interfaces. Interfaces of surgical tools, implants, prostheses and orthopedic apparatus have to fit as much optimal as possible. This property avoids complications, malfunctionality, breaks, corrosion of interfaces, friction problems, wear of materials, histocompatibility inmunological reactions, postoperative pain, and a wide of unpredictable complication possibilities.

Pediatric surgery is more complicated in general for CAM than the adult's one. The children organism and constitution is in dynamic-growing continuous evolution, and the physical activity of a child is higher than the adult. It is not unfrequent to find diseases related to growth during childhood. This difficulty implies that prostheses or artificial implants could have a short time of utility, unless that adaptable implants/prostheses are set. The ligaments elasticity, tissular viscoelasticity, and bone hardness also changes in time during the children's growth stages - for instance, the bone hardness of knee articulation. Apart from that the physical/sporting/gaming activity of kids is higher compared to adults. Computational Biomechanics and computational dissection CAD and CAM design constitutes an useful tool to resolve all these pediatric biomedical pathologies. Statistical database for pediatric bones is more difficult to be obtained.

\begin{tabular}{|c|c|}
\hline \multicolumn{2}{|c|}{$\begin{array}{l}\text { COMPUTATIONAL DISSECTION BIOMEDICAL } \\
\text { APPLICATIONS }\end{array}$} \\
\hline $\begin{array}{l}\text { SPINAL SURGICAL } \\
\text { PATHOLOGYFIEL } \\
\text { D }\end{array}$ & APPLICATIONS \\
\hline Spinal CAD & $\begin{array}{l}\text { All tools and prostheses } \\
\text { optimal design }\end{array}$ \\
\hline Spinal CAM & $\begin{array}{l}\text { All tools and prostheses } \\
\text { optimal } \\
\text { design }\end{array}$ \\
\hline $\begin{array}{l}\text { Spine tools and } \\
\text { apparatus }\end{array}$ & $\begin{array}{l}\text { Spinal instrumentation, } \\
\text { implants and deformity } \\
\text { correction } \\
\text { implant-bone prostheses, } \\
\text { interfaces instrumentation, } \\
\text { all kind of screws, rods, } \\
\text { grips, distractors, screw- } \\
\text { insertion-angle optimization } \\
\text { for a wide range of implants }\end{array}$ \\
\hline Prostheses & $\begin{array}{l}\text { All types of implants, } \\
\text { artificial disks, clamps, } \\
\text { stabilizers, etc }\end{array}$ \\
\hline Orthe & $\begin{array}{l}\text { Spondylolisthesis, } \\
\text { scoliosis,and all other types } \\
\text { of deformations orthopedics } \\
\text { apparatus }\end{array}$ \\
\hline Pre-o & $\begin{array}{l}\text { Pre-operation } \\
\text { computational } \\
\text { simulations/optimization, } \\
\text { pre-operation design of } \\
\text { implants or necessary new } \\
\text { tools at theatre }\end{array}$ \\
\hline Post-operation & $\begin{array}{l}\text { Complications prevention, } \\
\text { post-operation } \\
\text { imaging tracking, } \\
\text { computational } \\
\begin{array}{l}\text { design of } \\
\text { additional pecking, }\end{array} \\
\text { implants }\end{array}$ \\
\hline Rehabili & $\begin{array}{ll}\text { Post-surgery } & \text { orthopaedics } \\
\text { rehabilitation } & \text { for motion }\end{array}$ \\
\hline
\end{tabular}




\begin{tabular}{|c|c|}
\hline & $\begin{array}{l}\text { preservation apparatus, } \\
\text { prostheses, electric- } \\
\text { mechanical implants }\end{array}$ \\
\hline Spine Deformations & $\begin{array}{l}\text { All types of spinal tools for } \\
\text { correction or balance }\end{array}$ \\
\hline $\begin{array}{l}\text { Preventive } \\
\text { Medicine }\end{array}$ & $\begin{array}{l}\text { Statistics for prevention of } \\
\text { incidence/prevalence of } \\
\text { spinal diseases, statistic } \\
\text { models for disease evolution }\end{array}$ \\
\hline $\begin{array}{l}\text { Surgical theatre } \\
\text { work }\end{array}$ & $\begin{array}{lr}\text { Optimization of all types of } \\
\text { tools } & \text { functionality, } \\
\text { interfaces, } & \text { resistance, } \\
\text { corrosion } & \text { protection, } \\
\text { instrumentation } & \text { ductility } \\
\text { and/or fatigue } & \end{array}$ \\
\hline $\begin{array}{ll}\text { Pediatric } & \text { Spinal } \\
\text { Surgery } & \end{array}$ & $\begin{array}{l}\text { Deformation, stabilization, } \\
\text { correction prostheses, spinal } \\
\text { pediatry instrumentation in } \\
\text { general }\end{array}$ \\
\hline $\begin{array}{l}\text { Pediatric } \\
\text { orthopedics }\end{array}$ & $\begin{array}{l}\text { Pediatrics stabilization } \\
\text { orthopaedics }\end{array}$ \\
\hline
\end{tabular}

Table 2.- Synopsis of biomedical applications of computational dissection presented in this study.

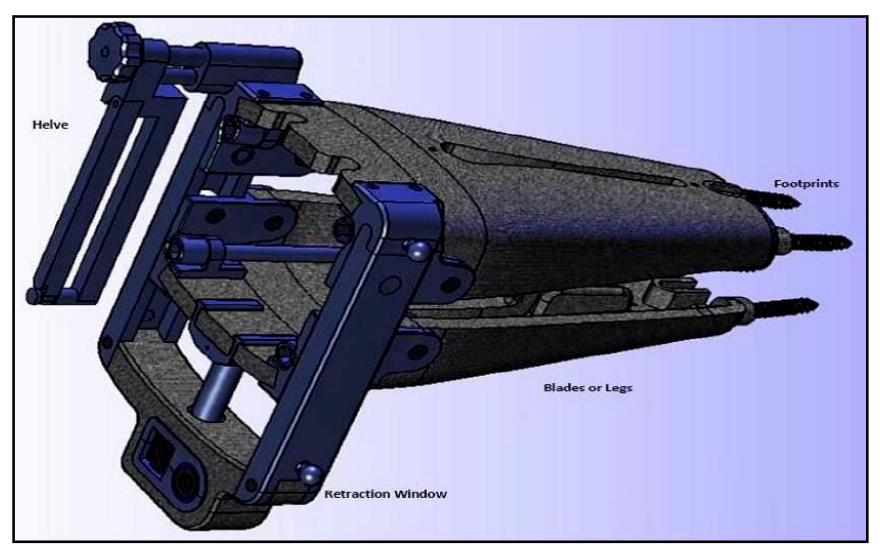

Figure 12.- Example of the parallel-spinal vertebral distractor designed in 2007 [Casesnoves, Lawson, 2007, 10]. The insertion angle of screws was optimized with large statistical CAD numerical database.The main engineering feature of this distractor is its capability to separate vertebras in parallel [Casesnoves, 2007].

\section{PRE-HYPOTHESES IN SPINAL EVOLUTION}

In this section, pre-hypotheses about the spinal evolution interrelation with research advances and method-improvements related to spinal surgery are presented [Casesnoves, 2020]. Table 3 shows basis of pre-hypotheses based on author's research from previous literature contributions $[1,2,18]$.

These pre-hypotheses are set to demonstrate the importance of spinal evolution for getting practicaltangible advances in surgery and spinal surgery. When the genetically-evolution change from quadrupedal to bipedal locomotion was developed, the spine of hominoids, its biomechanics, tissue, bone geometry and size, were modified. Not only the spine evoluted, but also, for instance, the significant changes involved the whole cardiovascular systemlikewise crucial for human physiology. The peripheric circulation required more hydrodynamic energy and its hydrodynamics parameters were modified in thorax and legs [18].

The gravity center of body changed position towards S2 level (approximately). Flexion, extension, rotation, and combined movements of these had different biomechanical forces and moment magnitudes/distributions.

The hominoids adaptation-evolution to standing up posture changed abruptly the thorax load direction for a cranial-caudal vertical load supported by hipfemur frame, legs, and knees [2,18]. That is the reason of the importance of the knee articulation/ligaments and its frequent traumatological diseases.

During evolution, the femur length became longer, and marked mainly the difference in height among individuals. The pre-hypothetical motives are getting faster and better walk and run. Faster and safer walk 
could be achieved with body mass of thoraxabdomen centered and bounded within a shorther thorax-abdomen anatomical system. This weigth is then fixed, and supported by hip and knees. Oscillating body-mass distributions during walk and run could constitute a dynamics-mechanical difficulty/inconvenient.

\section{BIOMECHANICAL-SPINAL-EVOLUTION PRE-HYPOTHESES [Casesnoves, 2020]}

\section{'Genetic evolution/adaptation of hominoids for bipedal locomotion caused significant} biomechanical changes in human spinal system, both biomechanical and physiological'

\begin{tabular}{|l|l|}
\hline SPINAL & $\begin{array}{l}\text { EVOLUTIONARY } \\
\text { EXPLANATION }\end{array}$ \\
\hline LENGTH & $\begin{array}{l}\text { Shorter for lower } \\
\text { moment } \\
\text { Magnitudes and shorther } \\
\text { thorax }\end{array}$ \\
\hline $\begin{array}{l}\text { VERTEBRAL } \\
\text { BODY }\end{array}$ & $\begin{array}{l}\text { Wider and stronger as } \\
\text { the load was cranial- } \\
\text { caudal }\end{array}$ \\
\hline GRAVITY & $\begin{array}{l}\text { Towards approximately } \\
\text { S2 level }\end{array}$ \\
\hline MENTER & $\begin{array}{l}\text { Flexion,extension, } \\
\text { rotation flexion-rotation } \\
\text { extension-rotation } \\
\text { CHANGES }\end{array}$ \\
$\begin{array}{l}\text { lateral flexion lateral } \\
\text { extension biomechanical } \\
\text { parameters transformed }\end{array}$ \\
\hline SITTING DOWN & $\begin{array}{l}\text { Also changed forces } \\
\text { distribution and lumbar } \\
\text { flexion while sitting } \\
\text { down posture, it } \\
\text { increased lumbar disk } \\
\text { loads }\end{array}$ \\
\hline
\end{tabular}

Table 3.- Resume of pre-hypothesis statement for biomechanical evolutionary changes in hominoids [Casesnoves, 2020].

Therefore, all these evolutionary changes enhance and justify the importance of spinal biomechanics scientific research. Applications in CAD and CAM are practical/useful to resolve, simulate and optimize the spinal surgery techniques in future.

\section{SURGICAL ROBOTICS AND BIOMEDICAL CYBERNETICS APPLICATIONS}

CAD and CAM spinal database and simulations are useful for the design of surgical robotics. Robots can reduce the failure rate when extreme precision on bone is required-e. g., drilling or driving screws into bone. FEM models can be incorporated to the integrated system for robot precise performance [20]. Telesurgery for remote operations constitute an advantage because intervertions at several centers can be teledriven from a single telerobotic unit [20]. Besides, telerobotic surgery is useful for interventions at remote or insolated geographically hospitals. For example, extreme weather conditions, geophysics catastrophes/disasters, and in a tentative guess, for aerospace aircrafts emergency surgery. Spine is a rigid body from mechanical point of view. This property is an essential advantage for robotic usage. Imaging contrast and sharpness of bone and surrounding biomechanical structures of spine constitute a plus for optimal applications-CT, MRI, X-ray, etc. The pre and post-operative plans and their execution could be more precise and accurate in spinal surgery. For instance, [20], Romed Robot Integrated System can be used for classical spinal fusion operations. This robot offers high precisión when drilling bone. Actually, Robotic Surgery constitutes a promising specialization with many applications in traumatology. Veterinary surgical robotics concepts 
[Casesnoves, 2020], could constitute a source of future-advance in the animal surgery area also.

Additionally, Forensic Robotics [Casesnoves, 2019] concepts may be useful in future. Advantages would be that monitoring or anesthesia are unnecessary, the absence of risks for patient life if failure happens, and the time schedule without constraints. Artificial Intelligence (AI) can also be incorporated. Mechanical tissue models and algorithms, [20], form part of the robot integrated system. Table 4 shows Forensic Robotics concepts, [Casesnoves, 2019-20] with advantages and inconvenients.

\begin{tabular}{|l|l|}
\hline \multicolumn{2}{|c|}{ FORENSIC ROBOTICS ADVANTAGES } \\
[Casesnoves, 2019]
\end{tabular}

\begin{tabular}{|l|l|}
\hline TRAINING & $\begin{array}{l}\text { staff to use robots and technical } \\
\text { apparatus }\end{array}$ \\
\hline TECHNICAL & $\begin{array}{l}\text { A number of technical staff is } \\
\text { necessary for calibration and } \\
\text { preparation/reparation of all } \\
\text { apparatus. If these fail, the task } \\
\text { has to be made by classical } \\
\text { forensics }\end{array}$ \\
\hline
\end{tabular}

Table 4.Brief of Forensic Robotics. The advantages and inconvenients are detailed.

\section{DISCUSSION AND CONCLUSIONS}

This article has proven improvements and advances related to previous developments of computational anatomical dissection [2,3,8-12]. The real 3D anatomical model of the vertebras offers a number of research possibilities for data/imaging extraction. Further, biomedical applications for CAM follow straightforward.

Computational dissection results can be set into three groups. First one is the matrix ROIs selection. ROIs can be obtained for any imaging part provided sufficient amount of cloud data within matrix. Second, computational dissection of anatomical segments by using the imaging-matrix elements. This is the longer, more time-consuming and difficult task. Third, plane dissections for segments, vertebras, disks, or combination of each another. This third method/option is useful, for instance, for measuring the size of a vertebra, determine clearly the pathology of vertebral body/facet - and several other possibilities. Specifically, the consequences for diagnosis of degeneration of Specimen 1 are proven sharply [8-12].

ROIs dissection is useful for detailed analysis of very specific segments of vertebras/disks. However, tiles of 
imaging subroutines have to be adapted for acceptable visualization - this task is time consuming. Inconvenients found in this study are that specimens correspond to elderly patients. A large scale of data coming from wide range of anatomical specimens of several ages could provide with database for CAD and CAM. Statistically, to define numerical data as sufficiently reliable, at least 25 samples should be required-imaging modelling, incidence/prevalence pathologies determination, extrapolation to distributions/statistical-models, CAM, etc [12].

The second part of the article deals with applications of these methods can be considered acceptable and practical. Namely, Biomedical, Spinal Evolution applications, and Robotics-Cybernetics surgery ones. The determination of curvatures, facet smoothness, concavities geometrical data, angles of curvature, size of surfaces, and bone-degeneration/deformation of vertebras, are useful for surgical industry. These purposes are suitable for precise surgical tools manufacturing, spinal stabilization, artificial implants/prostheses, orthopaedic apparatus/instruments, surgical robotics and computational preparation/design of intervention $[1,2,6-10,13]$.

Post-operative results verification could be complemented with imaging comparison to real cadaveric specimen images.

The second part of this article that deals with biomedical applications and prospective of surgical robotics is linked to first part. Forensic Robotics engineering concepts, [Casesnoves, 2020], were presented. One significant advantage of Forensic Robotics is the unlimited time to perform a precise study of corpses, or corpse cavities/targeted organs, collection of particular-concrete tissue samples, when a forensic diagnosis is strictly required [Casesnoves, 2020]. A number of biomechanical pre-hypotheses for spinal evolution are presented. Spinal genetic development studies are useful for prospective / consictent developments of surgery in future.

Concisely, this paper has demonstrated how in modern computational surgery 3D imaging information can be useful for biomedical advances today.

\section{SCIENTIFIC ETHICS STANDARDS}

This contribution is based on Graphical Visualization-Optimization methods for different clinical laboratory cadaveric specimens of lumbar spine, namely Specimen 1. 3D Imaging Computational Methods were created by Francisco Casesnoves from 2007-2019. Forensic Robotics Integrated Systems engineering-concepts were developed by Casesnoves in July 2020. PreHypotheses in Spinal Biomechanical Evolution were done by Francisco Casesnoves 2019-2021. This article has a few previous paper information and figures, whose inclusion is essential to make the contribution understandable. Figure 3 is a programming modification for demonstrative purposes [10]. This study was carried out, and their contents are done according to the European Union Technology and Science Ethics. Reference, 'European Textbook on Ethics in Research'. European Commission, Directorate-General for Research. Unit L3. Governance and Ethics. European Research Area. Science and Society. EUR 24452 EN [21,22]. This research was completely done by the author, the software, calculations, images, mathematical propositions and statements, reference citations, and text is original for the authors. When anything is taken from a source, it is adequately recognized. Ideas from previous publications were emphasized due to a clarification aim, [21,22]. 


\section{REFERENCES}

[1]. Panjabi, M, White, A. Clinical Biomechanics of the Spine. Lippincott. 1980.

[2]. Ben, E, Gomez-Olivencia, A, Kramer,P. Spinal Evolution. Springer. 2019.

[3]. Casesnoves, F. Software Programming with Lumbar Spine Cadaveric Specimens for Computational Biomedical Applications, International Journal of Scientific Research in Computer Science, Engineering and Information Technology (IJSRCSEIT), ISSN : 2456-3307, Volume 7 Issue 1, pp. 07-13, January-February 2021

[4]. Casesnoves, F. The Numerical Reuleaux Method, a computational and dynamical base with applications. First Part. Lambert Academic Publishing. ISBN-10 3659917478. 2019.

[5]. Casesnoves, F. Die Numerische ReuleauxMethode Rechnerische und Dynamische Grundlagen mit Anwendungen (Erster Teil). ISBN-13 : 978-620-0-89560-8, ISBN-10: 6200895600. Publishing House: Sciencia Scripts. 2019-20.

[6]. Casesnoves F, Suzenkov A. Mathematical Models in Biotribology with 2D-3D Erosion Integral-Differential Model and Computational-Optimization/Simulation

Programming. International Journal of Scientific Research in Computer Science, Engineering and Information Technology. 2017 IJSRCSEIT | Volume 2 | Issue 3 | ISSN : 24563307.

[7]. Casesnoves F. Mathematical Models and Optimization of Erosion and Corrosion. Taltech University Press. Doctoral Thesis. ISSN 25856898. 2018.

[8]. Casesnoves, F. 'Computational Simulations of Vertebral Body for Optimal Instrumentation Design'. ASME Journal of Medical Devices
(Research Paper). Author: F Casesnoves .Journal of Medical Devices. June 2012. Volume 6. Issue 2/021014.11 pages.http://dx.doi.org/10.1115/1.4006670.

[9]. Casesnoves, F, Lawson ,J. “An Optimization Method for anterior vertebral body morphometry to enhance surgical devices". Lecture-Poster. 2008 SIAM Conference of Imaging Science. San Diego CA, USA. July 2008.

[10]. Casesnoves, F."Computational Simulations of Anterior Vertebral Surface for Statistical Optimization in Surgical Instrumentation Design". ASME Peer-reviewed Conference Paper and Poster. Proceedings of the 2010 Design of Medical Devices Conference. April 13-15, 2010, Minneapolis, MN, USA.

[11]. Casesnoves, F."Spinal Biomechanics Mathematical Model For Lumbar Intervertebral Ligaments". 2011 SIAM Conference on Computational Science and Engineering. Reno, Nevada,USA.

[12]. Casesnoves, F. Applied inverse methods for optimal geometrical-mechanical deformation of lumbar artificial disks/implants with Numerical Reuleaux method. 2D comparative simulations and formulation. Ethan Publishing Computer Science Applications. 2015, 2, 4, pp. 1-10. [USA Congress Library registration].

[13]. Casesnoves, F. 'A Monte-Carlo Optimization method for the movement analysis of pseudorigid bodies'. 10th SIAM Conference in Geometric Design and Computing, Texas, San Antonio, USA. Contributed Talk. November 2007.

[14]. Casesnoves, F. 'Applied Inverse Methods for Deformable Solid Dynamics/Kinematics in Numerical Reuleaux Method (NRM)'. International Journal of Numerical Methods and Applications. volume 9(2) 2013.Pages 109131 peer-reviewed International 
Mathematical/Computation Journal Article. This article is specially innovative in Inverse Problems applications for deformable solids kinematics/dynamics, further publications are included in United States Congress Library and Numerical Reuleaux Method is accepted by scientific community as an innovative dynamics method in deformable solids with mechanical, biomechanical and aerospace applications. New applications of this method will be probably found significantly in future.

[15]. Casesnoves, F. Nonlinear comparative optimization for biomaterials wear in artificial implants technology. Presented in Applied Chemistry and Materials Science RTU2018 Conference Proceedings. 2018.

[16]. Casesnoves, F. Applied Inverse Methods for Optimal Deformation of Lumbar Artificial Disk/Implants with Numerical Reuleaux Method and 3D Voxelization-Computational Simulations. American Institute of Science. Bioscience and Bioengineering. Vol. 1, No. 4, 2015, pp.

94-105. http://www.aiscience.org/journal/bio.

[17]. Casesnoves, F. 3D Improved mathematical model for lumbar intervertebral ligaments (LILs). Proceedings SIAM Life Sciences Conference joint to SIAM Annual Conference San Diego. 2012, pp. 25-27.

[18]. Darwin,C. The origin of species. Barnes \& Noble Classics. 2004.

[19]. Todinov, M. Reliability and Risk Models. Wiley. 2005.

[20]. Rosen, J, Hannaford, B. Satava, R. Surgical Robotics. Wiley. 2011.

[21]. 'European Textbook on Ethics in Research'. European Commission, Directorate-General for Research. Unit L3. Governance and Ethics. European Research Area. Science and Society. EUR 24452 EN.
[22]. The European Code of Conduct for Research Integrity. Revised Edition. ALLEA. 2017.

\section{AUTHOR'S BIOGRAPHY}

Francisco Casesnoves is Engineering and Natural Sciences PhD by Talllinn University of Technology (started thesis in 2016, thesis defence/ $\mathrm{PhD}$ earned Defence in December 2018, official graduate Diploma 2019), Estonia, and computationalengineering/physics independent researcher at COE, MSc-BSc, Physics/Applied-Mathematics (Public Eastern-Finland-University), Graduate-with-MPhil, in Medicine and Surgery (Public Madrid University Medicine School). Casesnoves studied always in public-educational institutions. His education/scientific vocation was motivated very young, by Profs C Navamuel and I Vela, in Renaissance-Humanism ideas-later on with the motivation manuscripts of Nobel and Von Helmholtz prizes Santiago Ramon y Cajal. His constant service to International Scientific Community and Estonian technological progress (2016-present) commenced in 1985 with publications in Medical Physics, with further specialization in optimization methods in 1997 at Finland - at the moment approximately 100 recognized publications with 50 papers. His main branch is Computational-mathematical Nonlinear/Inverse Methods Optimization. Casesnoves best-achievement is the Numerical Reuleaux Method in dynamics and nonlinearoptimization [books 2019-2020]. Casesnoves scientific service since 2016 to the Free and Independent Republic of Estonia for technological development (and also at Riga technical University, Power Electrical and Electronics Department) is about 27 physics-engineering articles, two books, and 1 industrial radiotherapy project associated to Europe Union EIT Health Program (Tartu University, 2017). 


\section{Cite this article as :}

Francisco Casesnoves, "Advanced Computational Dissection for Lumbar Cadaveric Specimens with Applications", International Journal of Scientific Research in Computer Science, Engineering and Information Technology (IJSRCSEIT), ISSN : 2456-3307, Volume 7 Issue 2, pp. 83-97, March-April 2021. Available at doi : https://doi.org/10.32628/CSEIT217210 Journal URL : https://ijsrcseit.com/CSEIT217210

\section{APPENDICES}

\section{APPENDIX I. ANATOMICAL COMPARISON WITH SPECIMENS OF [3]}

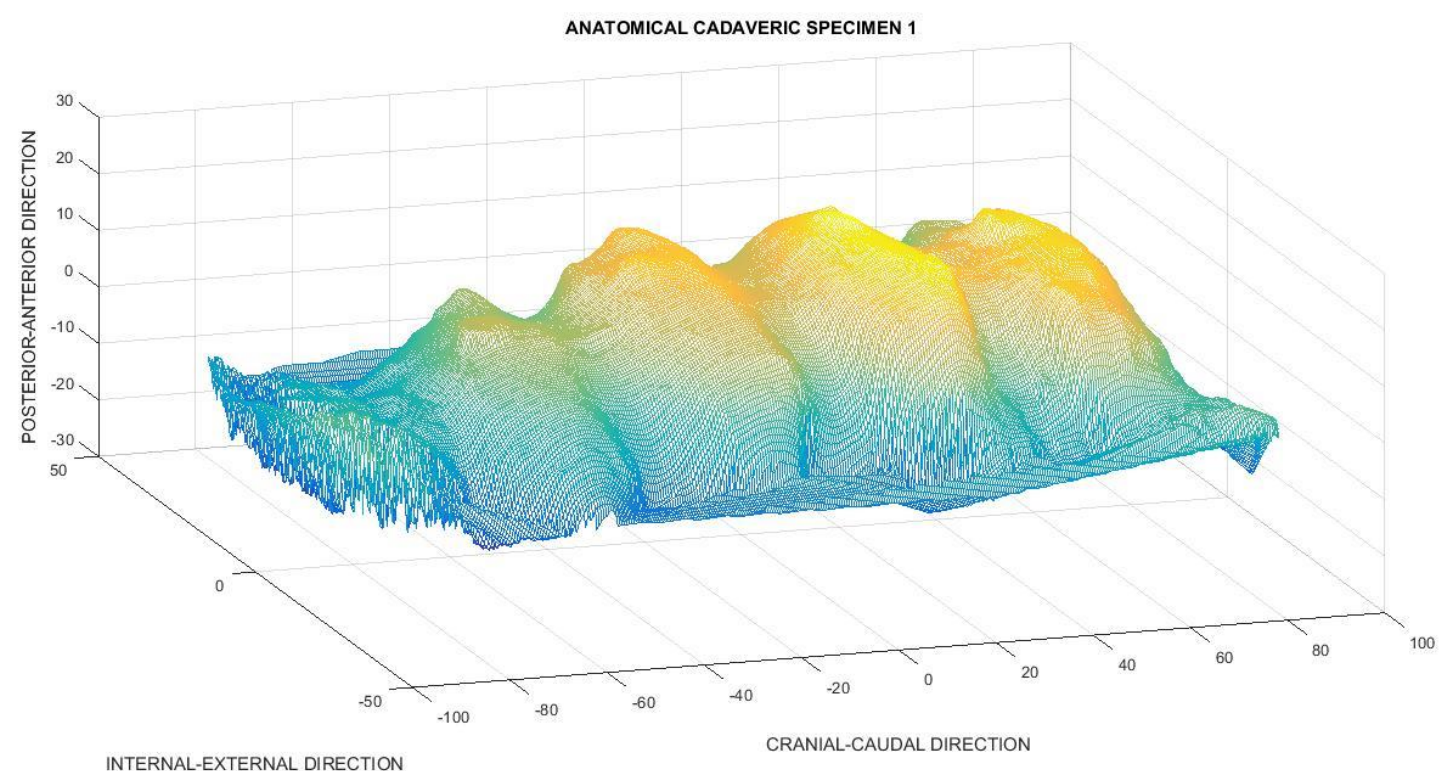

Appendix I.Figure 1.-Specimen 1 large view to show differences with Specimens of [3].

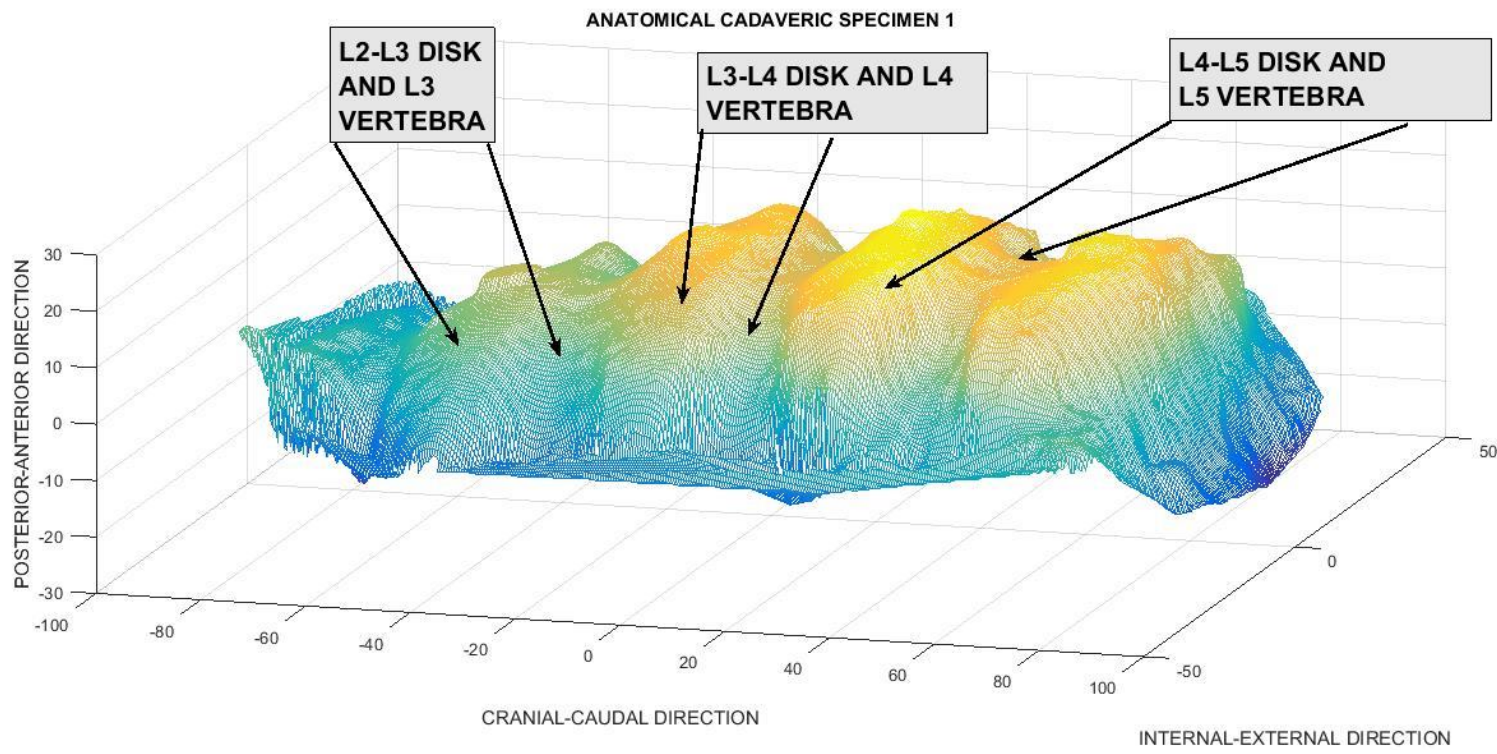

Appendix I.Figure 2.-Specimen 1 large view to show differences with Specimens of [3]. 


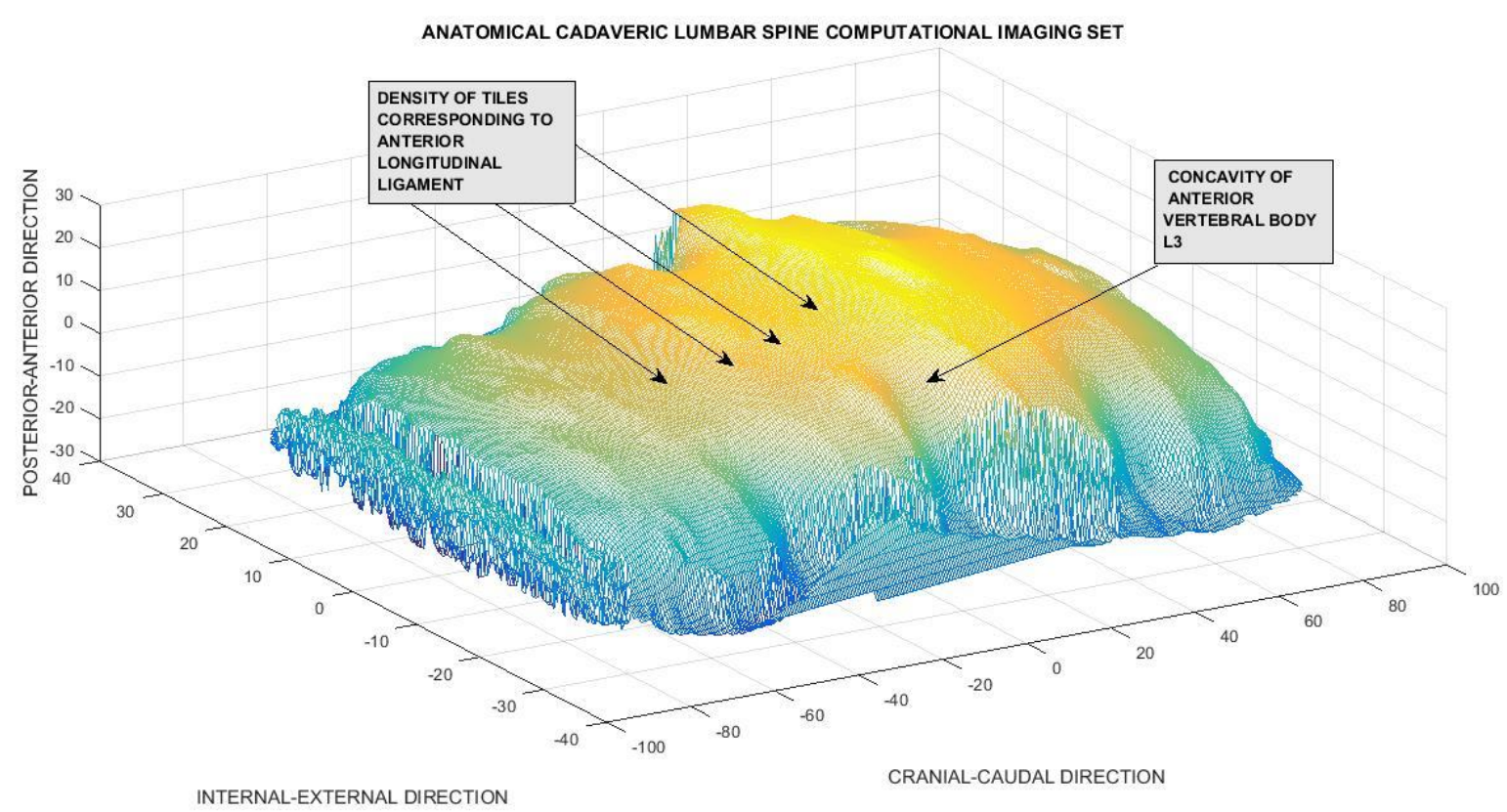

Appendix I. Figure 3.-From [2], cranial view showing traces of anterior longitudinal ligament and L4 vertebral body surface [erratum, in legend should be L4, not L3].Differences with Specimen 1 are clear.

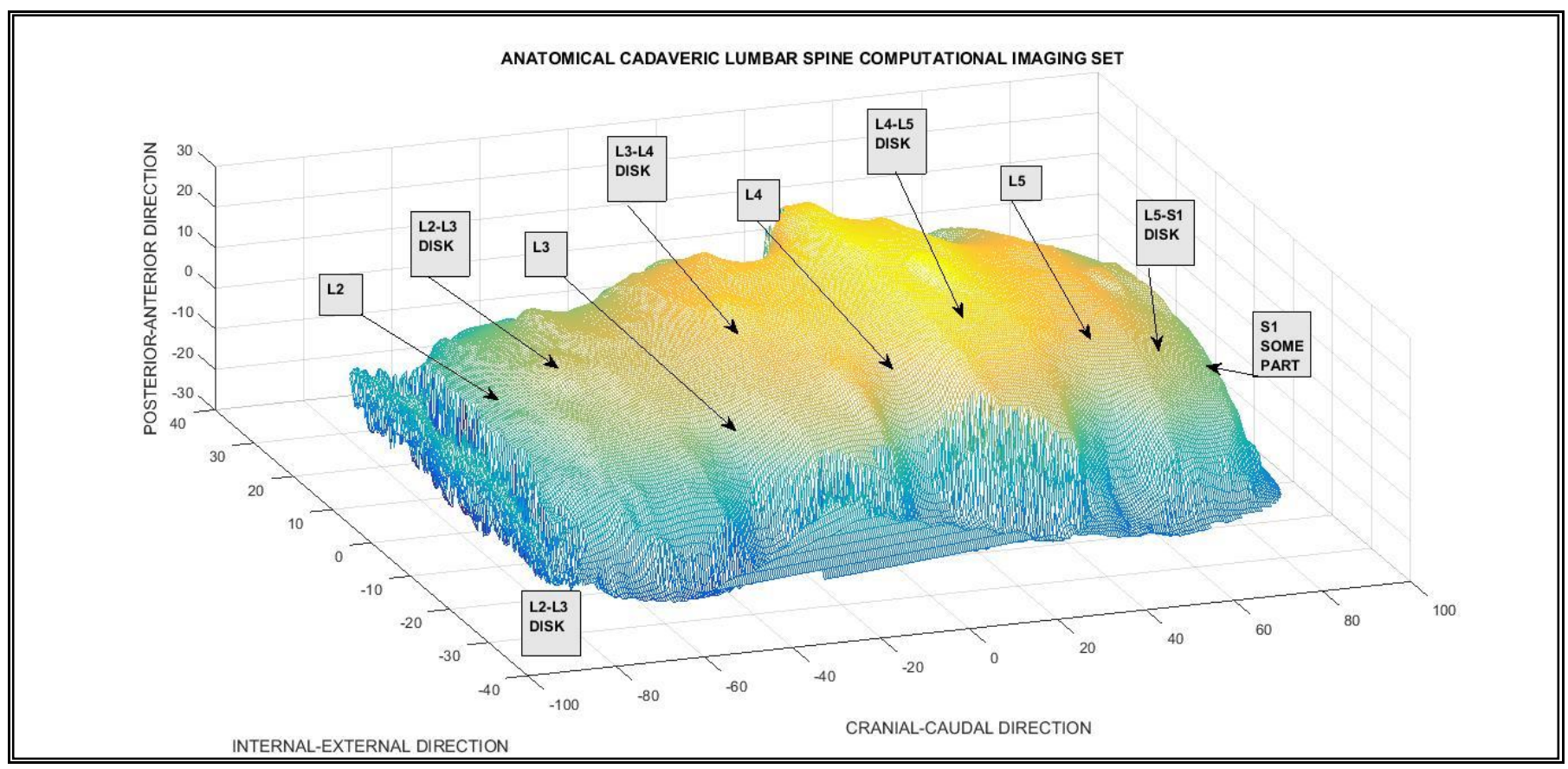

Appendix I. Figure 4.-From [3], cranial view showing traces of anterior longitudinal ligament and L4 vertebral body surface [erratum, in legend should be L4, not L3]. Differences with Specimen 1 are clear. 